cambridge.org/hyg

\section{Original Paper}

*Deceased

Presented in part at the Journées annuelles de santé publique (2015)

Cite this article: Ouhoumanne N, Lowe A-M, Fortin A, Kairy D, Vibien A, K-Lensch J, Tannenbaum T-N, Milord F (2018). Morbidity, mortality and long-term sequelae of West Nile virus disease in Québec. Epidemiology and Infection 146, 867-874. https://doi.org/ $10.1017 /$ S0950268818000687

Received: 15 September 2017

Revised: 19 January 2018

Accepted: 28 February 2018

First published online: 28 March 2018

Key words:

Morbidity/mortality; sequelae; West Nile virus

Author for correspondence:

François Milord, E-mail: francois.milord@ usherbrooke.ca

\title{
Morbidity, mortality and long-term sequelae of West Nile virus disease in Québec
}

N. Ouhoumanne ${ }^{1}$, A-M. Lowe ${ }^{1}$, A. Fortin ${ }^{1}$, D. Kairy ${ }^{2,3}$, A. Vibien ${ }^{4}$, J. K-Lensch ${ }^{4}$, T-N. Tannenbaum ${ }^{5, *}$ and F. Milord ${ }^{1,6}$

${ }^{1}$ Institut national de santé publique du Québec, Montréal, Québec, Canada; ${ }^{2}$ Université de Montréal, Montréal, Québec, Canada; ${ }^{3}$ Centre de recherche interdisciplinaire en réadaptation du Montréal métropolitain, Montréal, Québec, Canada; ${ }^{4}$ Centre intégré de santé et de services sociaux de la Montérégie-Est, St-Hyacinthe, Québec, Canada; ${ }^{5}$ Direction de santé publique de Montréal, Montréal, Québec, Canada and ${ }^{6}$ Université de Sherbrooke, Sherbrooke, Québec, Canada

\begin{abstract}
We aimed to describe the clinical characteristics of West Nile patients reported in Québec in 2012 and 2013 and to document physical, mental and functional status 24 months after symptom onset according to illness severity. The cases were recruited by a public health professional. Data were collected from public health files, medical records and two standardised phone questionnaires: the Short Form-36 and the Instrumental Activities of Daily Living. In all, 92 persons participated in the study (25 had West Nile fever (WNF), 18 had meningitis and 49 had encephalitis). Encephalitis participants were older, had more underlying medical conditions, more neurological symptoms, worse hospital course and higher lethality than meningitis or WNF participants. Nearly half of the surviving hospitalised encephalitis patients required extra support upon discharge. At 24-month follow-up, encephalitis and meningitis patients had a lower score in two domains of the mental component: mental health and social functioning $(P=0.0025$ and 0.0297 , respectively) compared with the norms based on age- and sex-matched Canadians. Physical status was not affected by West Nile virus (WNV) infection. In addition, 5/36 (15\%) of encephalitis, $1 / 17(6 \%)$ of meningitis and $1 / 23(5 \%)$ of WNF participants had new functional limitations 24 months after symptom onset. In summary, mental and functional sequelae in encephalitis patients are likely to represent a source of long-term morbidity. Preventive measures should target patients at higher risk of severe illness after WNV infection.
\end{abstract}

\section{Introduction}

West Nile virus (WNV) infection is endemic in North America. More than 41000 cases of WNV-related illnesses and 2000 deaths have been reported in the USA between the introduction of the virus in 1999 and 2015 [1]. During the same period, 5310 cases have been reported in Canada [2]. In Québec, the first documented cases happened in 2002. After a quiet period (2004-2010), the province experienced an outbreak between 2011 and 2013 [3].

WNV causes an asymptomatic infection in $80 \%$ of cases and flu-like symptoms (West Nile fever, WNF) in $20 \%$. In one out of 150 infections, a severe illness occurs with neurological involvement like aseptic meningitis, encephalitis or acute flaccid paralysis (AFP) [4, 5]. The risk of severe illness increases in older persons, in those with compromised immune systems and those with underlying medical conditions, like hypertension and diabetes [6-8]. Surveillance data from the province of Québec indicate that the incidence of neurological disease increases approximately 1.6-fold for each decade of life [9]. WNV infection and particularly neurological disease have been associated with mild-to-severe clinical manifestations [10]. WNF and West Nile meningitis (WNM) are generally associated with a favourable outcome. This is different for West Nile encephalitis (WNE) where altered consciousness is present in up to $75 \%$ of patients and $10-30 \%$ of them may die [9-13]. WNE patients may also require rehabilitation services or support at home after acute care discharge [11-13].

Unlike acute morbidity and mortality, long-term physical, cognitive as well as functional sequelae associated with WNV disease are less well known. A recent systematic review, which included 29 studies on long-term sequelae of WNV-related illness, showed that the most common persistent physical sequelae reported were weakness, fatigue, myalgia and headache [14]. The most common persistent cognitive sequelae were memory loss, depression and difficulty concentrating and the most common persistent functional sequelae was difficulty doing activities of daily living [14]. In studies comparing sequelae between neuroinvasive and non-neuroinvasive patients, a poorer physical and functional prognosis was noted for neuroinvasive patients, while cognitive status was similar in both groups. However, these studies varied by study design, sample size, methods used to measure sequelae (subjective $v s$. objective measurements), duration of follow-up and outcomes measured. In addition, few of these 
studies compared WNE and WNM. The authors of the review highlighted the need for more primary studies with larger sample size, longer follow-up periods and use of matched controls [14].

The objectives of this study are (1) to describe the clinical characteristics of patients according to illness severity, and (2) to prospectively document physical, mental and functional status up to 24 months after symptom onset using standardised questionnaires. The results of this study will help in the understanding of WNV infection burden in Québec to support planning and prevention efforts.

\section{Methods}

\section{Study population}

WNV infection is a reportable disease in Québec. Physicians and laboratories must report all WNV-positive cases to the regional public health boards, who conduct an epidemiological investigation in order to document the infection, determine the likely place of acquisition and collect socio-demographic and clinical information, such as date of illness onset and clinical syndrome (i.e. uncomplicated fever, meningitis, encephalitis and AFP). In this investigation, the treating physician provides clinical information to the public health nurse while the patient or his family clarifies where the exposure occurred. The data are entered into the integrated system for public health monitoring of WNV (ISPHM-WNV), a provincial electronic surveillance system for WNV disease that includes information on humans, mosquitoes and animals [15]. During the period 2012-2013, 155 symptomatic WNV cases were reported in Québec. We asked regional public health boards to approach them to see whether they were willing to be contacted about the study. Written consent to participate in a phone interview and to get access to their medical chart was then obtained from eligible patients by a research nurse. For those younger than 18 years old, the consent was obtained from the parents or legal guardians, and for deceased persons, the consent to get access to their medical chart was obtained from the families. These latter were included only for morbidity and mortality evaluation but excluded from phone interview. The study protocol was submitted to the Comité d'éthique de santé publique from the Institut national de santé publique du Québec, which delivered a favourable opinion towards it [16].

\section{Data collection}

\section{Chart review}

The medical records of patients hospitalised or seen in an emergency department were reviewed by a research nurse to collect information on medical history, clinical and neurological symptoms and diagnostic test results. For patients who consulted in private practice only, medical history and clinical symptoms were collected from the epidemiological investigation form filled by the regional public health board.

\section{Phone questionnaires}

For eligible participants, two standardised phone questionnaires were administered by a research nurse 12 months (2013 cases only) and 24 months after symptom onset to document their physical, mental and functional status.

Physical and mental health statuses were assessed using the Short Form (SF)-36 [17]. Canadian population norms are available for this instrument, which permits external comparisons [18]. The SF-36 scale contains 36 items grouped into eight health concepts or domains: physical function $(\mathrm{PH})$, physical role limitations (RP), bodily pain (BP), general health $(\mathrm{GH})$, social functioning (SF), mental health (MH), emotional role limitations (RE) and vitality (VT). Each item was scored from 0 (worst health state) to 100 (best health state), and the scores of each of the eight domains could be tabulated as the physical and mental component summary scores. The physical component summary includes $\mathrm{PH}$, $\mathrm{RP}, \mathrm{BP}$ and GH domains and the mental component summary includes SF, MH, RE and VT domains.

Functional status was assessed using the Instrumental Activities of Daily Living (IADL) [19]. The IADL scale contains eight items that assess a person's ability to perform tasks before and after illness: using a telephone, go shopping, food preparation, doing laundry, housekeeping, using mode of transportation, owning medications and handling finances. Each item was scored as 0 'unable or partially able' to 1 'able'. Item responses are summed to derive a scale score with higher scores indicating greater independence.

These two questionnaires are available and have been validated both in English and in French.

\section{Case definitions}

In the ISPHM-WNV, all laboratory diagnoses of WNV infection by IgM capture enzyme immunoassays either from serum or cerebrospinal fluid (CSF) samples are included. In Québec, after a first IgM-positive case has been confirmed with plaque reduction neutralization test, all other IgM-positive cases occurring in the same season are considered to be laboratory confirmed. Cases are further classified according to their clinical presentation as WNF (an acute systemic febrile illness), WNM (with stiff neck and CSF pleocytosis), WNE (with altered mental status), West Nile meningo-encephalitis (WNME) and AFP (polio-like myelitis or Guillain-Barre syndrome) [20].

\section{Data analysis}

For the analysis, one case with missing information about clinical syndrome was excluded and one case of muscular weakness was classified as AFP after reviewing his medical record. WNME ( $n$ $=18)$ and AFP $(n=3)$ cases were combined with the WNE ( $n$ $=27$ ) cases given the similar clinical presentation. All analyses were performed according to three clinical categories (WNF, WNM and WNE). Proportions were compared using $\chi^{2}$ test or Fisher's exact test when appropriate; distributions of age and hospital stay were compared with exact Wilcoxon rank-sum (Kruskal-Wallis) non-parametric test.

Mean scores of each of the eight domains of the SF-36 were compared to age- and sex-matched Canadian norms [18] using $t$ tests [21]. Physical and mental component summary T-scores were standardised to a mean of 50 (s.D. $=10)$, with a score $>50$ representing better than average and $<50$ poorer than average function [22]. For 2013 participants $(n=20)$, SF-36 and IADL were administered 12 and 24 months after symptoms onset. Results were similar for both time points and only results at 24 months are thus presented.

Analyses were performed using SAS version 9.1 (SAS Institute Inc., Cary, NC, USA) and a two-sided $P<0.05$ was considered statistically significant.

\section{Results}

From the 155 symptomatic WNV 2012-2013 patients, 93 (60\%) agreed to participate in the study (Fig. 1). The non-participants were the WNV patients who could not be reached by their 


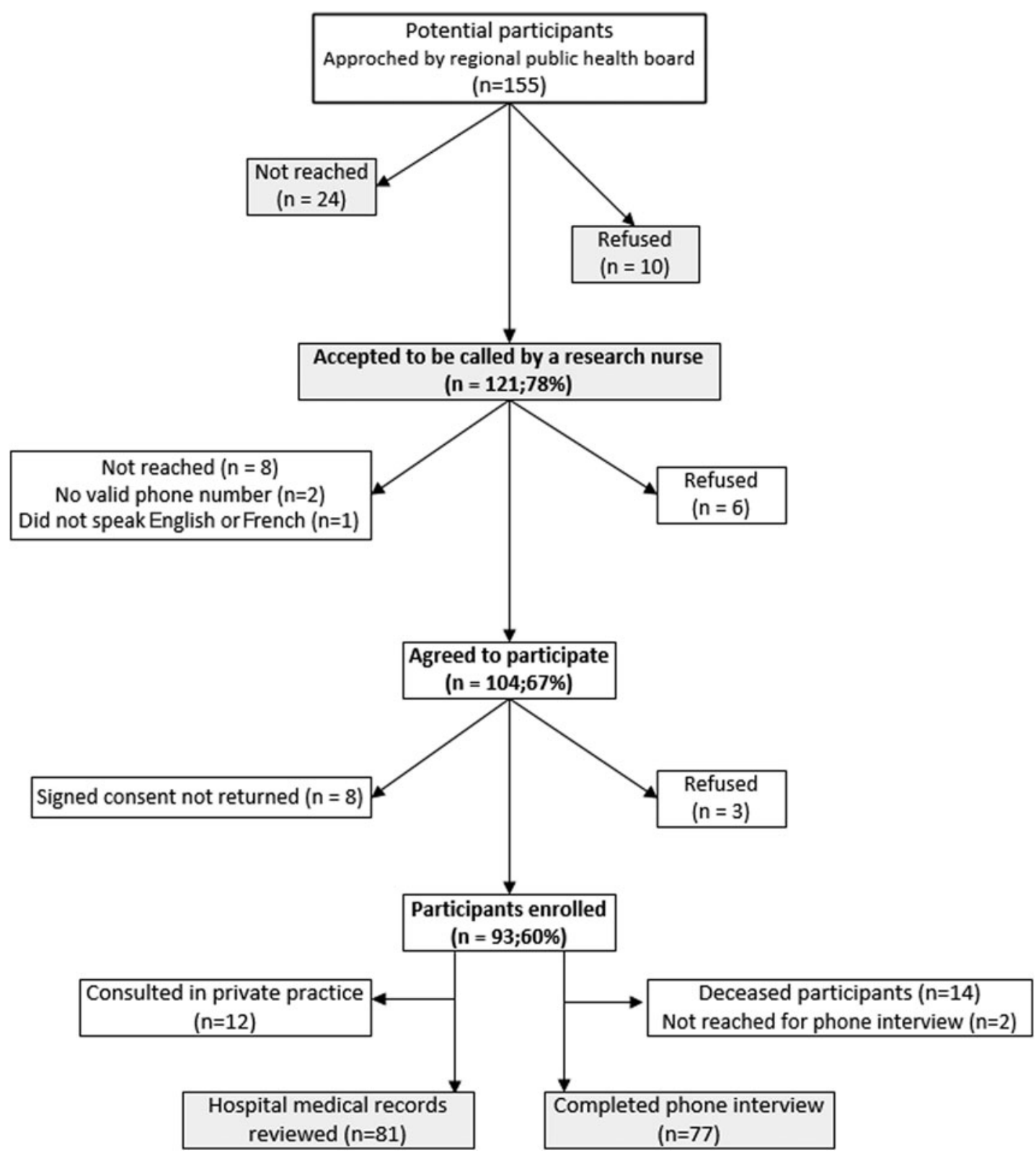

Fig. 1. Study flow diagram.

regional public health board or those who refused to be contacted for the study. Participants and non-participants were comparable with regard to demographic (except for sex where more women agreed to participate $(54 \%$ vs. $36 \%, P=0.026))$ and illness severity (hospitalization, $76 \%$ vs. $71 \%, P=0.437$; clinical syndrome, $73 \%$ vs. $68 \%$ had neurological symptoms, $P=0.502$ ). More families of deceased patients agreed to participate in the study (15\% vs. $5 \%)$, but the difference was not statistically significant $(P=$ 0.07). Medical records were available for 81 (87\%) participants (71 hospitalizations and 10 emergency department visits), and of the 79 known to be alive at the time of survey, 77 (97\%) patients completed the phone interview at 24 months.

\section{Clinical characteristics}

Demographic and clinical characteristics of participants are presented in Table 1. Among 92 patients, WNF, WNM and WNE accounted for $27 \%, 20 \%$ and $53 \%$, respectively. WNE participants were significantly older that WNM $(P=0.0002)$ or WNF participants $(P=0.0006)$. More pre-existing medical conditions (hypertension, heart disease and diabetes) were observed among WNE participants. The majority of WNE $(48 / 49 ; 98 \%)$ and WNM (17/18; 94\%) participants were hospitalised, compared with $20 \%$ $(5 / 25)$ of WNF $(P<0.0001)$. The median hospital stay was however longer among WNE participants compared with WNM $(P$ $<0.0001)$ or WNF $(P=0.010)$. In addition, $22 / 48(46 \%) \mathrm{WNE}$ hospitalised patients were admitted to the intensive care (vs. nil WNM or WNF patients). Among them, 12 required intubation.

Fever, fatigue and headache were frequent and noted in more than $70 \%$ of participants (Table 2). Chills, weakness and anorexia were significantly more frequent among WNE and WNM participants, gastrointestinal symptoms among WNM and rash among WNF and WNM participants (Table 2). The association with gastrointestinal symptoms persisted even after controlling for 
Table 1. Demographic and clinical characteristics of 92 WNV patients in Québec, 2012-2013

\begin{tabular}{|c|c|c|c|c|c|c|}
\hline & WNF $(n=25)$ & WNM $(n=18)$ & $\mathrm{WNE}^{\mathrm{a}}(n=49)$ & $\begin{array}{l}P \text {-value for } \\
\text { WNE vs. WNM }\end{array}$ & $\begin{array}{l}P \text {-value for } \\
\text { WNE vs. WNF }\end{array}$ & $\begin{array}{l}P \text {-value for } \\
\text { WNM vs. WNF }\end{array}$ \\
\hline Age median years (range) & $53(21-92)$ & $53(30-73)$ & $68(12-86)$ & 0.0002 & 0.0006 & 0.571 \\
\hline Age group years & & & & 0.0002 & 0.0006 & 0.789 \\
\hline$<20$ & 0 & 0 & $2(4 \%)$ & & & \\
\hline $20-49$ & $7(28 \%)$ & $7(39 \%)$ & $4(8 \%)$ & & & \\
\hline $50-59$ & $11(44 \%)$ & $7(39 \%)$ & $8(16 \%)$ & & & \\
\hline$\geqslant 60$ & $7(28 \%)$ & $4(22 \%)$ & $35(71 \%)$ & & & \\
\hline Male sex & $8(32 \%)$ & $8(44 \%)$ & $24(49 \%)$ & 0.741 & 0.163 & 0.405 \\
\hline $\begin{array}{l}\text { Pre-existing medical } \\
\text { conditions }\end{array}$ & $11(44 \%)$ & $10(56 \%)$ & $40(82 \%)$ & 0.029 & 0.001 & 0.454 \\
\hline Hypertension & $6(24 \%)$ & $5(28 \%)$ & $30(61 \%)$ & 0.015 & 0.002 & 1.000 \\
\hline Cardiovascular disease & $3(12 \%)$ & $3(17 \%)$ & $26(53 \%)$ & 0.005 & 0.0003 & 0.682 \\
\hline Diabetes & $1(4 \%)$ & $2(11 \%)$ & $14(29 \%)$ & 0.201 & 0.014 & 0.562 \\
\hline Lung disease & $3(12 \%)$ & $2(11 \%)$ & $8(16 \%)$ & 0.717 & 0.740 & 1.000 \\
\hline Liver disease & $2(8 \%)$ & $3(17 \%)$ & $7(14 \%)$ & 1.000 & 0.709 & 0.634 \\
\hline Renal failure & $1(4 \%)$ & 0 & $7(14 \%)$ & 0.176 & 0.252 & 1.000 \\
\hline Cancer & $3(12 \%)$ & 0 & $6(12 \%)$ & 0.181 & 1.000 & 0.252 \\
\hline HIV + /immunosuppression & $1(4 \%)$ & 0 & $4(8 \%)$ & 0.567 & 0.656 & 1.000 \\
\hline $\begin{array}{l}\text { History of neurological } \\
\text { symptoms }\end{array}$ & $4(16 \%)$ & $1(6 \%)$ & $6(12 \%)$ & 0.664 & 0.725 & 0.380 \\
\hline Hospitalisation & $5(20 \%)$ & $17(94 \%)$ & $48(98 \%)$ & 0.468 & $<0.0001$ & $<0.0001$ \\
\hline $\begin{array}{l}\text { Days hospitalised, } \\
\text { median (range) }\end{array}$ & $4(2-12)$ & $4(1-36)$ & $13(3-663)$ & $<0.0001$ & 0.010 & 0.692 \\
\hline Intensive care & 0 & 0 & $22 / 48(46 \%)$ & 0.0002 & 0.068 & - \\
\hline Complications & 0 & $3 / 17(18 \%)$ & $22 / 48(46 \%)$ & 0.047 & 0.068 & 1.000 \\
\hline Discharge sequelae & $1 / 5(20 \%)^{c}$ & $5 / 17(29 \%)$ & $27 / 48(56 \%)$ & 0.089 & 0.176 & 1.000 \\
\hline
\end{tabular}

anclude West Nile encephalitis ( $n=27)$, meningo-encephalitis $(n=18)$ and acute flaccid paralysis $(n=3)$.

${ }^{\mathrm{b}}$ Headaches, dementia or brain trauma.

${ }^{c}$ Continue to experience persistent headaches.

risk factors such as pre-existing medical conditions and age (data not shown). Rash was more frequently observed among younger participants (median age 55 years) compared with those without rash (median age 64 years, $P=0.0034$ ). In addition, when analyses were restricted to participants aged $<55$ years, no difference in proportion of rash were observed among the three clinical syndromes (data not shown).

Information on neurological symptoms was available only for participants with medical record $(n=81)$. Overall, neurological symptoms were more common among WNE participants (Table 3). Of the $49 \mathrm{WNE}, 44(90 \%)$ had altered consciousness including five patients with coma. Other common neurological symptoms included neuromuscular weakness (76\%), cranial neuropathy (67\%), cognitive impairment (53\%) and neck stiffness (49\%).

Among hospitalised participants, only 20 (42\%) WNE were discharged home without support compared with 15 (88\%) WNM and four $(80 \%)$ WNF participants, $P=0.001$. Ten $(21 \%)$ WNE, one $(6 \%)$ WNM and one (20\%) WNF participants were discharged home with support. Six (13\%) and three (6\%) WNE participants were transferred to rehabilitation institution and long-term care hospital, respectively. Ten (21\%) WNE and one (6\%) WNM participants died during hospitalization, in addition to three WNE participants who died during the follow-up study (data not shown).

\section{Physical and mental health status 24 months after symptom onset}

For analyses of physical and mental status, WNE and WNM participants were grouped because they presented similar results (Table 4). Overall, 20 (38\%) and $29(55 \%)$ neuroinvasive participants and nine (39\%) and $12(52 \%)$ non-neuroinvasive participants had low physical component scale (PCS) and mental component scale (MCS), respectively. Compared with age- and sex-matched Canadian norms, mental health and social functioning were the only affected domains in cases with neuroinvasive disease $(P=0.0025$ and 0.0297 , respectively). The differences were not statistically significant for other domains of the MCS and all domains of the PCS.

Analyses of physical and mental status were also made according to the pre-existing medical conditions status (Table 5). Compared with age- and sex-matched Canadian norms, participants with one or more pre-existing medical conditions had 
Table 2. Clinical manifestation at the presentation of 92 WNV patients in Québec, 2012-2013

\begin{tabular}{|c|c|c|c|c|c|c|}
\hline & WNF $(n=25)$ & WNM $(n=18)$ & $\mathrm{WNE}^{\mathrm{a}}(n=49)$ & $\begin{array}{l}P \text {-value for } \\
\text { WNE vs. WNM }\end{array}$ & $\begin{array}{l}P \text {-value for } \\
\text { WNE vs. WNF }\end{array}$ & $\begin{array}{l}P \text {-value for } \\
\text { WNM vs. WNF }\end{array}$ \\
\hline Fever $>38^{\circ} \mathrm{C}$ & $19(76 \%)$ & $17(94 \%)$ & $49(100 \%)$ & 0.268 & 0.0009 & 0.209 \\
\hline Headache & $18(72 \%)$ & $17(94 \%)$ & $30(61 \%)$ & 0.007 & 0.358 & 0.111 \\
\hline Gastrointestinal symptoms ${ }^{b}$ & $11(44 \%)$ & $17(94 \%)$ & $32(65 \%)$ & 0.026 & 0.078 & 0.0008 \\
\hline Chills & $7(28 \%)$ & $14(78 \%)$ & $31(63 \%)$ & 0.381 & 0.004 & 0.002 \\
\hline Weakness & $4(16 \%)$ & $10(56 \%)$ & $33(67 \%)$ & 0.372 & $<0.0001$ & 0.009 \\
\hline Myalgias/muscle aches & $11(44 \%)$ & $11(61 \%)$ & $19(39 \%)$ & 0.282 & 0.792 & 0.454 \\
\hline Rash & $14(56 \%)$ & $9(50 \%)$ & $14(29 \%)$ & 0.146 & 0.021 & 0.697 \\
\hline
\end{tabular}

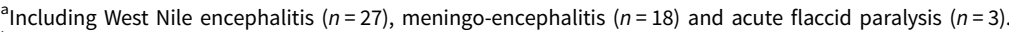

${ }^{\mathrm{b}}$ Nausea, vomiting, diarrhoea or abdominal pain.

${ }^{\mathrm{C} C o u g h, ~ w h e e z i n g ~ o r ~ p h a r y n g i t i s . ~}$

significantly lower score in two domains of the PCS (bodily pain; $P=0.039$ and general heath; $P=0.030$ ) and two domains of the MCS (mental health; $P=0.009$ and social functioning; $P=$ 0.003 ). While participants without pre-existing medical conditions had significantly higher score in three domains of the PCS (physical functioning, role physical and bodily pain) and similar score in all domains of the MCS than general population.

\section{Functional status 24 months after symptom onset}

Participants were asked to report their ability to perform tasks before and 24 months after symptom onset (Table 6). Excluding five participants with baseline functional impairment (two WNF, one WNM and two WNE), one (5\%) WNF, one (6\%) WNM and five (15\%) WNE participants reported functional sequelae 24 months post-infection. Most reported difficulties were food preparation, shopping and transportation. These participants were older (median age of 63 years, range of 55-83 years) and all had preexisting medical conditions.

\section{Discussion}

In our study, WNE participants were older, had more underlying medical conditions, more neurological symptoms and worse hospital course (longer hospital stay, intensive care, in-hospital complications and death) than WNM or WNF participants. Nearly

Table 3. Neurological manifestations of 80 WNV patients with medical charts, Québec, 2012-2013

\begin{tabular}{|c|c|c|c|c|c|c|}
\hline & WNF $(n=13)$ & WNM $(n=18)$ & $\mathrm{WNE}^{\mathrm{a}}(n=49)$ & $\begin{array}{l}P \text {-value for } \\
\text { WNE vs. WNM }\end{array}$ & $\begin{array}{l}P \text {-value for } \\
\text { WNE vs. WNF }\end{array}$ & $\begin{array}{l}P \text {-value for } \\
\text { WNM vs. WNF }\end{array}$ \\
\hline Altered consciousness $^{\mathrm{b}}$ & $1(8 \%)$ & $8(44 \%)$ & $44(90 \%)$ & $<0.0001$ & $<0.0001$ & 0.044 \\
\hline Cranial neuropathy & 0 & $3(17 \%)$ & $33(67 \%)$ & 0.0002 & $<0.0001$ & 0.245 \\
\hline Nuchal rigidity or neck stiffness & $1(8 \%)$ & $7(39 \%)$ & $24(49 \%)$ & 0.462 & 0.009 & 0.095 \\
\hline Sensory disturbances & 0 & $2(11 \%)$ & $17(35 \%)$ & 0.071 & 0.012 & 0.496 \\
\hline Dizziness & $2(15 \%)$ & $12(67 \%)$ & $14(29 \%)$ & 0.004 & 0.483 & 0.009 \\
\hline Balance problems & 0 & $1(6 \%)$ & $9(18 \%)$ & 0.266 & 0.183 & 1.000 \\
\hline Extrapyramidal disorders & 0 & 0 & $7(14 \%)$ & 0.176 & 0.328 & - \\
\hline
\end{tabular}

ancluding West Nile encephalitis $(n=27)$, meningo-encephalitis $(n=18)$ and acute flaccid paralysis $(n=3)$.

${ }^{\mathrm{b}}$ Confusion, drowsiness, stupor, delirium or coma ( $n=5$, WNE).

${ }^{\mathrm{c}}$ Hypo- or hyper-reflexia, myoclonus, weakness or paralysis $(n=3, \mathrm{WNE})$.

${ }^{\mathrm{d}}$ Tremor or vertigo.

eOcular pain, decreased visual acuity or photophobia. 
Table 4. Physical and cognitive health status 24 months after WNV symptom onset, Québec, 2012-2013

\begin{tabular}{|c|c|c|c|}
\hline SF-36 outcome & Canadian norms mean & WNF, $n=23$ mean $(95 \% \mathrm{Cl})$ & WNM and WNE, $n=53$ mean $(95 \% \mathrm{Cl})$ \\
\hline Physical functioning & 82 & $84(76-92)$ & $80(72-88)$ \\
\hline Role physical & 80 & $78(67-89)$ & $81(74-88)$ \\
\hline Bodily pain & 75 & $69(60-78)$ & $73(65-81)$ \\
\hline General health & 75 & $70(61-79)$ & $72(67-78)$ \\
\hline Vitality & 66 & $61(53-69)$ & $62(56-68)$ \\
\hline Social functioning & 86 & $79(70-88)$ & $77^{\star}(70-84)$ \\
\hline Role emotional & 85 & $84(77-91)$ & $81(75-87)$ \\
\hline Mental health & 78 & $75(68-82)$ & $70^{\star \star}(65-75)$ \\
\hline Physical component scale & 49 & $49(45-53)$ & $52(49-55)$ \\
\hline Mental component scale & 53 & $48(44-52)$ & $45(42-48)$ \\
\hline Poor physical component scale $(<50), n(\%)$ & & $9(39 \%)$ & $20(38 \%)$ \\
\hline Poor mental component scale $(<50), n(\%)$ & & $12(52 \%)$ & $29(55 \%)$ \\
\hline
\end{tabular}

${ }^{\star} P=0.020$ for comparison with age- and sex-matched Canadian norms.

${ }^{\star \star} P=0.003$ for comparison with age- and sex-matched Canadian norms.

half of surviving hospitalised encephalitis participants required extra support upon discharge. These results are consistent with what was found in previous studies [13, 23-26].

Like in other viral infection of the central nervous system, nausea and vomiting occur in WNV infection due to the inflammatory response around the brain. In our study, WNM participants have significantly more gastrointestinal symptoms than WNF or WNE and the association persisted even after controlling for risk factors. It has been reported that WNM patients frequently require hospitalization for pain control for severe headache or rehydration because of prolonged nausea and vomiting [10]. In addition, the increased frequency of rash seen in WNF and WNM patients was associated with their younger age, which is consistent with the previous findings [27].
Despite a favourable outcome, 5/25 (20\%) WNF participants were hospitalised with a median hospitalization stay of 4 days, one of them needed extra support upon discharge and one reported deterioration of functional status up to 24 months. In another study, $31 \%$ of 98 WNF patients required hospitalization and $84 \%$ reported limitations in their household activities in the following weeks [28]. In our study, hospitalised WNF had similar demographic and clinical profiles (i.e. mean age, pre-existing medical conditions and clinical symptom at presentation) as WNE participants, which could contribute to their hospitalization and poor outcome. It is also possible that misclassification occurred and that some WNF cases had undetected mild neuroinvasive disease because lumbar puncture and cerebral scans were not performed on most of these patients $[13,24,28]$. In

Table 5. Physical and cognitive health status 24 months after WNV symptom onset according to pre-existing medical conditions, Québec, 2012-2013

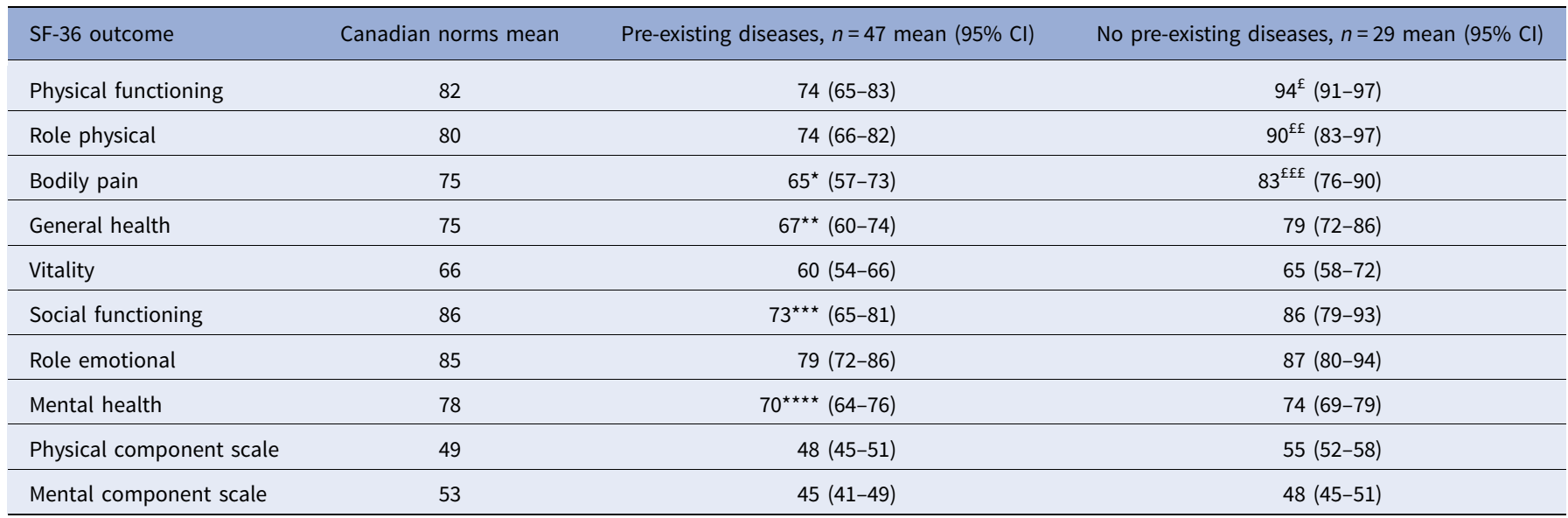

${ }^{*} P=0.039$ for comparison with age- and sex-matched Canadian norms.

${ }^{*} * P=0.03$ for comparison with age- and sex-matched Canadian norms.

${ }^{* \star *} P=0.003$ for comparison with age- and sex-matched Canadian norms

${ }^{\star * \star \star *} P=0.009$ for comparison with age- and sex-matched Canadian norms.

${ }^{\varepsilon} P=0.0008$ for comparison with age- and sex-matched Canadian norms.

${ }^{E \mathcal{E}} P=0.038$ for comparison with age- and sex-matched Canadian norms.

${ }^{\mathrm{Eff}} P=0.048$ for comparison with age- and sex-matched Canadian norms. 
Table 6. Impaired functional status at baseline and 24 months after WNV symptom onset, Québec, 2012-2013

\begin{tabular}{|c|c|c|c|c|c|c|}
\hline \multirow[b]{2}{*}{ Difficulty to } & \multicolumn{2}{|c|}{ WNF $(n=23)$} & \multicolumn{2}{|c|}{ WNM $(n=17)$} & \multicolumn{2}{|c|}{ WNE $(n=36)$} \\
\hline & $\begin{array}{l}\text { Before } \\
\text { symptom } \\
\text { onset }\end{array}$ & $\begin{array}{l}24 \text { months after } \\
\text { symptom onset }\end{array}$ & $\begin{array}{l}\text { Before } \\
\text { symptom } \\
\text { onset }\end{array}$ & $\begin{array}{l}24 \text { months after } \\
\text { symptom onset }\end{array}$ & $\begin{array}{l}\text { Before } \\
\text { symptom } \\
\text { onset }\end{array}$ & $\begin{array}{l}24 \text { months after } \\
\text { symptom onset }\end{array}$ \\
\hline Using a phone & - & - & - & - & - & - \\
\hline Go shopping & $1(4 \%)$ & $2(9 \%)$ & $1(6 \%)$ & $2(12 \%)$ & $1(3 \%)$ & $5(14 \%)$ \\
\hline $\begin{array}{l}\text { Food } \\
\text { preparation }\end{array}$ & - & - & - & - & - & $5(14 \%)$ \\
\hline Housekeeping & - & - & - & - & $1(3 \%)$ & $3(8 \%)$ \\
\hline Doing laundry & - & - & - & $1(6 \%)$ & - & $2(6 \%)$ \\
\hline $\begin{array}{l}\text { Using mode of } \\
\text { transportation }\end{array}$ & $1(4 \%)$ & $1(4 \%)$ & $1(6 \%)$ & $1(6 \%)$ & - & $4(11 \%)$ \\
\hline $\begin{array}{l}\text { Owning } \\
\text { medications }\end{array}$ & $1(4 \%)$ & $2(9 \%)$ & - & - & $1(3 \%)$ & $3(8 \%)$ \\
\hline $\begin{array}{l}\text { Handling } \\
\text { finances }\end{array}$ & - & - & - & - & - & $1(3 \%)$ \\
\hline $\begin{array}{l}\text { At least one } \\
\text { difficulty }\end{array}$ & $2(9 \%)$ & $3(13 \%)$ & $1(6 \%)$ & $2(12 \%)$ & $2(6 \%)$ & $7(19 \%)$ \\
\hline
\end{tabular}

our study, 3/5 hospitalised WNF did not have a lumbar puncture.

One strength of our study is the use of standardised and validated questionnaires to document long-term sequelae of $\mathrm{WNV}$ infection, which provided quantifiable measures and allowed comparison with other studies using the same instruments. At 24-month follow-up, only neuroinvasive patients had a lower score in two domains of the mental component, mental health and social functioning, compared with the general population. This result could be attributable to the high proportion of preexisting medical conditions among them. Indeed, participants with pre-existing medical conditions, such as hypertension, cardiovascular disease and diabetes, had a lower score in both mental (mental health and social functioning) and physical (general health and bodily pain) components, whereas participants without these conditions had better or similar score compared with the general population. These results are consistent with the previous findings indicating that pre-existing medical conditions are a prognostic factors for long-term WNV-related sequelae [25]. In the study of Loeb et al., 156 Canadian patients were followed up to 36 months to assess long-term physical and mental status [25]. Most cases recovered after 1 year, but recovery was delayed in patients with neuroinvasive disease (only for physical function) and in those with underlying medical conditions (for both physical and mental function), whereas an absence of underlying medical conditions was associated with a faster rate of recovery. One important difference between this study and our study was the exclusion of patients with AFP, which have poor long-term outcomes [29]. Another difference was the younger age and less common underlying medical conditions in this study compared with our study, which could explain the overall favourable outcomes in the Canadian study. In a series of seven AFP cases, mental component score normalised at 2 years, while the physical component score stayed below normal [30], but these results are based on patients with this specific neurological manifestation. Sejvar et al. noted significant lower SF-36 scores in all eight physical and mental domains in $22 \mathrm{WNM}$ and $16 \mathrm{WNE}$ patients compared with pre-illness scores at 18 months post-infection [31].

We also used IADL to measure functional sequelae. Among our participants, 5/36 (15\%) WNE, $1 / 17$ (6\%) WNM and 1/23 (5\%) WNF had new functional limitations 24 months after symptom onset. Most reported difficulties were food preparation, shopping and transportation. The difference was not statistically significant probably due to the low sample size. Using the same questionnaire, Klee et al. showed that 10/35 (29\%) of hospitalised WNV patients still had some functional sequelae 1 year after acute illness [12]. Other studies using self-reported outcomes showed that difficulties with the activities of daily living were the most common functional sequelae in WNV infection [14].

There seems to be further discrepancies among studies between follow-up assessments using standardised questionnaires and selfreported outcomes [12, 13, 32, 33]. For example, a prospective study of $157 \mathrm{WNV}$-infected patients indicated that $40 \%(18 / 45)$ of participants were still reporting persistent physical and cognitive symptoms related to their infection up to 8 years later [13]. Self-reported sequelae studies could be limited by recall bias and the tendency of patients to overestimate their health problems.

Our study has a number of limitations. Although participation rate was high, subgroup analyses were based on a small number of cases and the power to detect statistically significant differences was reduced. Fourteen patients died (including 13 among WNE patients) and were excluded from the evaluation of long-term sequelae. Therefore, the impact of the disease could be underestimated particularly among WNE patients. In our study, we did not ask for persisting symptoms at 24 months. A combination of assessment methods would be most appropriate in order to obtain a full picture of the long-term impact of WNV infection. Finally, functional sequelae 2 years post-WNV infection were more frequent among WNE participants, but it could be a result of advancing age of these patients. 
This study provided the first portrait of WNV morbidity and mortality and long-term sequelae in the province of Québec. Our study showed that WNE patients were associated with more severe clinical manifestations and worst short-term outcomes. At 24 months, sequelae reported by these patients seem to be long lasting, but this could be due to the fact that persons with chronic diseases are more susceptible to develop severe WNV manifestations leading to a deterioration in their quality of life. This reinforces the idea that preventive measures against WNV infection need to be well communicated to the population and meticulously followed by persons with chronic diseases.

Acknowledgements. The authors would like to acknowledge the regional public health boards for approaching patients, research nurses for data collection, Melissa Trudeau for data entry and all patients who agreed to participate in this study.

Financial support. This study was funded by a research grant from Ministère de la santé et des services sociaux du Québec.

Declaration of Interest. None.

\section{References}

1. Centres for Disease Control and Prevention (2017) West Nile virus: Statistics \& Maps. Available at https://www.cdc.gov/westnile/statsmaps/ index.html. (Accessed 15 May 2017).

2. Public Health Agency of Canada (2017) Surveillance of West Nile virus. Available at https://www.canada.ca/en/public-health/services/diseases/westnile-virus/surveillance-west-nile-virus.html\#s1. (Accessed 15 May 2017).

3. Ouhoummane N, et al. West Nile Virus Infection Surveillance in Québec: 2013 season. Institut national de santé publique du Québec 2015, pp. 51, Available at https://www.inspq.qc.ca/publications/4143.

4. Carson PJ, et al. (2012) Neuroinvasive disease and West Nile virus infection, North Dakota, USA, 1999-2008. Emerging Infectious Diseases 18, 684-686.

5. Mostashari F, et al. (2001) Epidemic West Nile encephalitis, New York, 1999: results of a household-based seroepidemiological survey. Lancet London England 358, 261-264.

6. Lindsey NP, et al. (2012) Medical risk factors for severe West Nile virus disease, United States, 2008-2010. American Journal of Tropical Medicine and Hygiene 87, 179-184.

7. Murray K, et al. (2006) Risk factors for encephalitis and death from West Nile virus infection. Epidemiology and Infection 134, 1325-1332.

8. Murray KO, et al. (2009) Risk factors for encephalitis from West Nile virus: a matched case-control study using hospitalized controls. Zoonoses Public Health 56, 370-375.

9. Ferrouillet C, et al. (2012) Surveillance de l'infection par le virus du Nil occidental au Québec: saison 2012. Institut national de santé publique du Québec 2014, pp 51. Available at https://www.inspq.qc.ca/publications/ 1747.

10. Sejvar JJ (2014) Clinical manifestations and outcomes of West Nile virus infection. Viruses 6, 606-623.

11. Pepperell C, et al. (2003) West Nile virus infection in 2002: morbidity and mortality among patients admitted to hospital in southcentral Ontario. Canadian Medical Association Journal 168, 1399-1405.

12. Klee AL, et al. (2004) Long-term prognosis for clinical West Nile virus infection. Emerging Infectious Diseases 10, 1405-1411.
13. Murray KO, et al. (2014) Survival analysis, long-term outcomes, and percentage of recovery up to 8 years post-infection among the Houston West Nile virus cohort. PLOS ONE 9, e102953.

14. Patel H, Sander B and Nelder MP (2015) Long-term sequelae of West Nile virus-related illness: a systematic review. Lancet Infectious Disease 15, 951-959.

15. Gosselin P, et al. (2005) The Integrated System for Public Health Monitoring of West Nile Virus (ISPHM-WNV): a real-time GIS for surveillance and decision-making. International Journal of Health Geographics 4, 21.

16. Comité d'éthique de santé publique (2014) Avis sur le projet d'étude du fardeau de l'infection par le VNO au Québec: cohortes 2012 et 2013. Institut national de santé publique du Québec 2014, pp 2, Available at https://www.inspq.qc.ca/publications/1751.

17. Saris-Baglama RN, et al. (2010) QualityMetric Health Outcomes ${ }^{\mathrm{TM}}$ Scoring Software 4.0. Lincoln, RI: QualityMetric Inc.

18. Hopman WM, et al. (2000) Canadian normative data for the SF-36 health survey. Canadian Multicentre Osteoporosis Study Research Group. Canadian Medical Association Journal 163, 265-271.

19. Lawton MP and Brody EM (1969) Assessment of older people: selfmaintaining and instrumental activities of daily living. The Gerontologist 9, 179-186.

20. Ministère de la santé et des services sociaux du Québec (2016) Surveillance des maladies à déclaration obligatoire au Québec - Maladie d'origine infectieuse - Définitions nosologiques $10^{\mathrm{e}}$ édition 2016, pp. 120, Available at http://publications.msss.gouv.qc.ca/msss/fichiers/ 2016/16-268-03W.pdf.

21. Hays RD, et al. (1996) A microcomputer program (sf36. exe) that generates SAS Code for scoring the SF-36 Health Survey.

22. Maruish ME (ed.) (2011) User's manual for the SF-36 vs health survey, 3rd edn. LincoIn, RI: QualityMetric Incorporated.

23. Racsa L, et al. (2014) Clinical features of West Nile virus epidemic in Dallas, Texas, 2012. Diagnostic Microbiology and Infectious Disease 78, 132-136.

24. Gottfried K, Quinn R and Jones T (2005) Clinical description and follow-up investigation of human West Nile virus cases. Southern Medical Journal 98, 603-606.

25. Loeb M, et al. (2008) Prognosis after West Nile virus infection. Annals of Internal Medicine 149, 232-241.

26. Weatherhead JE, et al. (2015) Long-term neurological outcomes in West Nile virus-infected patients: an observational study. American Journal of Tropical Medicine and Hygiene 92, 1006-1012.

27. Murray KO, et al. (2008) Clinical investigation of hospitalized human cases of West Nile virus infection in Houston, Texas, 2002-2004. Vector-Borne and Zoonotic Diseases 8, e167-174.

28. Watson JT, et al. (2004) Clinical characteristics and functional outcomes of West Nile fever. Annals of Internal Medicine 141, 360-365.

29. Sejvar JJ, et al. (2006) West Nile virus-associated flaccid paralysis outcome. Emerging Infectious Diseases 12, 514-516.

30. Johnstone J, et al. (2011) Prognosis of West Nile virus associated acute flaccid paralysis: a case series. Journal of Medical Case Reports 5, 395.

31. Sejvar JJ, et al. (2008) Neurocognitive and functional outcomes in persons recovering from West Nile virus illness. Journal of Neuropsychology 2, 477-499.

32. Sejvar JJ, et al. (2003) Neurologic manifestations and outcome of West Nile virus infection. Journal of the American Medical Association 290, 511-515.

33. Carson PJ, et al. (2006) Long-term clinical and neuropsychological outcomes of West Nile virus infection. Clinical Infectious Diseases 43, 723-730. 